\title{
Article \\ Exploring Consumers' Purchase Intention of rPET Bottle-Based Apparel in an Emerging Economy
}

\author{
Thi Thanh An Luu (1) and John R. Baker* \\ Department of Business Administration, Quemoy National University, Kinmen County 892, Taiwan; \\ thanhan261185@gmail.com \\ * Correspondence: baker@email.nqu.edu.tw; Tel.: +886-082-314-409
}

\begin{abstract}
This study investigated the applicability (generalizability) of utilizing a partial least squares (PLS) model previously posed to predict consumer purchase intention (PI) of recycled plastics-sourced apparel in a developed economy to predict PI in an emerging economy. To explore the original model's generalizability, 495 Vietnam residents were surveyed via social media platforms (SMPs). Using partial least squares structural equation modeling (PLS-SEM) path analysis, it was found that three factors significantly affect PI (quality, sustainability, safety), albeit not the same organization of factors found to be significant in the original model. Thus, it is argued that consumer PI in emerging economies may not be entirely congruent with that of developing economies. As prior research of consumer PI of apparel made from recycled poly(ethylene terephthalate) (rPET) bottle fibers in emerging economies is limited, the results of this study, in support of open innovation, provide practical suggestions for marketers and a starting point for future investigations and discussions. The paper also discusses the findings' relevancy to other contexts and poses suggestions for further study.
\end{abstract}

Keywords: rPET; textile; poly(ethylene terephthalate); emerging economies; Vietnam; replication

Citation: Luu, T.T.A.; Baker, J.R. Exploring Consumers' Purchase Intention of rPET Bottle-Based Apparel in an Emerging Economy. J. Open Innov. Technol. Mark. Complex. 2021, 7, 22. https://doi.org/10.3390/ joitmc7010022

Received: 11 December 2020 Accepted: 6 January 2021 Published: 8 January 2021

Publisher's Note: MDPI stays neutral with regard to jurisdictional clai$\mathrm{ms}$ in published maps and institutional affiliations.

Copyright: (C) 2021 by the authors. Licensee MDPI, Basel, Switzerland. This article is an open access article distributed under the terms and conditions of the Creative Commons Attribution (CC BY) license (https:// creativecommons.org/licenses/by/ $4.0 /)$.

\section{Introduction}

Unsustainable manufacturing, consumption, and waste production have been cited as contributory factors of environmental deterioration and continue to be a global problem of pandemic proportions. In response, environmental awareness has been increasing since the 1980s, as consumers have been encouraged to recycle waste materials which are then channeled to environmentally friendly products. The impetus for this, Chang et al. [1] explain, is that recycling can provide a second life for waste that would otherwise fill limited and burgeoning landfill space by converting it into value-added and useful new products.

While concern for recycling began in the early 1980s, it was not until the 1990s that recycled-based apparel was considered to be environmentally expedient. Since then, this term has been interpreted in many ways, the earliest of which was consumers gifting clothing items to charity, family, and friends; selling them to second-hand shops; or repurposing them into household rags [2]. Later eco-friendly endeavors included recycling postconsumer clothing fibers for use in home furnishings and construction (concrete reinforcement and asphalt) [3,4]. More recent uses have been to advance what has been called a sustainable design movement [5], that is, undesigned and redesigned clothing (deconstructing clothing and then reconstructing the materials into new garments).

Such broadening of the recycling lens has opened up still more markets in the ecofriendly textile industry trajectory, one of which is the open innovation-driven technological advance of textile-grade fibers made from recycled poly(ethylene terephthalate) (rPET) bottles [6]; that is, chopping them into small flakes that are melted and then extruded into a form (e.g., threads) to be used in a new product [7]. This is highly appropriate as a million plastic bottles are purchased every minute globally [8], a great majority of which, in turn, negatively impact the environment, as they make up a large portion of 
household waste [9] and pollute landfills [10], aquatic ecosystems (i.e., waterways) [11], and oceans [12]. This negative impact is further compounded in that PET bottles are a nondegradable polymer [13].

Using rPET bottles in the manufacturing process has also been supported because utilizing postconsumer plastics reduces the energy [14] and related carbon footprint associated with textile production [15], an industry which is one of the world's largest polluters [16], second only to oil [17]. The industry's negative effect is further fueled by the fast fashion trend where apparel has a short wear life before being discarded in favor of new purchases [18,19]. An effective counter measure, for instance, is recycling $1 \mathrm{~kg}$ of PET bottles, which diverts 60 bottles from becoming pollutants, the amount needed to produce one jacket [20]. Recycling PET bottles into fibers for use in apparel manufacturing also makes sense, as synthetic polyester is the most frequently used material in the textile industry [6], and using recycled polyester fibers, which maintain many of the qualities of virgin fiber-based textiles [21], is easy and economical and requires only a fraction of the water needed in the making of new clothing, $90 \%$ less, a crucial reduction in nations that are experiencing water shortages [15].

Following the increases in consumer environmental and PET bottle reuse awareness, there has been a significant change in consumer consumption behavior [22,23]. In response to increased consumer demand, many apparel manufacturers have, using rPET-based fibers, innovatively introduced environmentally ethical products [24]. The first PET-textile application, for instance, was marketed by Armani, in 1995 (e.g., denim jeans). Soon thereafter, others followed (e.g., Adidas, Esprit, Levi Strauss, Patagonia, Timberland) $[9,15]$ that made a variety of products, to include those manufactured from ocean-sourced plastics.

Using rPET bottle-based fibers to produce eco-friendly apparel is one thing; marketing such products is another [16], especially when companies vie for market shares in such a highly competitive industry [25], because successfully marketing an innovative idea is a large part of open innovation [16]. As such, understanding the key factors that contribute to the formation of consumer purchase intention (PI) towards environmentally friendly apparel is crucial when developing effective marketing strategies. To explore this, consumer PI, a worthy and well-studied extension of Planned Behavior Theory [26], is commonly accepted as an important index to predict PI [27], a consumer's declaration of a predisposition to purchase, barring any significant contingencies in the market or the consumer's personal situation [28].

In line with this, there has been a growing amount of PI literature in the area of eco-friendly products. This is because companies and consumers have come to accept that a faulty, and all too common, economic model based on the linear consumption practice of consume-use-waste (where natural resources and raw materials are extracted, processed into final goods, and then become postconsumer waste) is unsustainable [29]. In contrast, more recently, companies and consumers have begun to look to a more circular economic model, one where resources are reused in a loop of production and usage that allows for the generation of more value [30].

Following this trend, a moderate number of explorations have investigated the broader lens of consumer intention with regard to eco-friendly apparel. This is because the literature has shown that consumer PI plays an important role in the circular economy [31]. Hence, it is crucial to understand consumer acceptance of such products [32]. These explorations have investigated a number of variables, to include consumer perceptions of (a) quality, (b) image, (c) sustainability/environmental benefits, and (d) safety.

In general, quality is a significant green PI factor [33]. Specifically, eco-friendly products are bought only if customers perceive them as comparable or superior to competitors' offerings [34]. This factor is further problematized as consumers have been found to associate green products with poorer performance, a perception which has been shown to negatively affect PI [35]. This is further compounded as consumers are generally unfamiliar with green apparel [36]. However, eco-friendly products are gradually becoming more 
accepted, and such concerns have been found to be mitigable through causal advertising which connects a product's green features with brand recognition [36].

Image, too, has been demonstrated to be an indicator. When products can be positioned in consumers' minds as environmentally friendly, for instance, such positioning can create a positive mental image, which, in turn, facilitates consumer PI [25]. This is because consumers who demonstrate a higher concern for the environment (e.g., those who recycle) have been found to be more likely to purchase eco-friendly materials [37], as they associate their behaviors with the eco-social belief that such actions can safeguard the environment [38] and that their individual contribution will have a positive effect [39,40]. This belief also contributes to consumers' psychometric self-identity and outward social image as eco-socially responsible green consumers [41,42].

A third area is related to sustainability/environmental benefits, or the belief that eco-friendly products' positive environmental impact can drive PI [43]. This assumption has the fashion industry differentiating products through eco-fashions [39]. And despite the hampering effect of advertising's "world-saving-overload" on consumer trust [39] and the resulting consumer skepticism toward green washing [28] (advertising that makes partial or unsupported ecological claims with the expectation that consumers will be unable to critically assess these claims) [44,45], causal marketing can positively affect consumer awareness which increases PI, especially with green consumers [46]. Moreover, environmental impact concerns have been demonstrated to be so cogent that consumers have been shown to express a willingness to pay (WTP) a higher premium for eco-friendly products $[39,47]$.

Another area, safety, has also been cited as contributory. A limited amount of research has found that consumers may negatively perceive recycled plastics used in circular production due to fears of contagion [47-49]. Meng and Leary [48], for example, found that rPET bottle-based apparel decreases PI as consumers negatively perceive the garment's safety (e.g., maintaining thoughts of contagion and contamination). Meng and Leary [48] further found that consumers have greater PI towards such products that do not touch the skin (e.g., handbags), as compared to those that require skin contact (e.g., T-shirts). Girao [49] reported similar results but added that fear can be reduced when consumers have previously purchased sustainable goods. Another important safety-related concern is a lack of consumer knowledge regarding product safeguards taken by manufacturers [50], a concern that can be mitigated when there is a transparency of the production process loop [39].

Noting the limited extant reclaimed plastics-based apparel literature regarding what impacts consumer PI in developed countries, Calvo-Porral and Levy-Mangin [29] posed a predictive partial least squares (PLS) regression model to predict consumer PI of recycled plastics-based apparel in a developing country (i.e., Spain). Despite their worthy contribution, a noticeable gap arises. That is, while rPET bottle-based apparel PI in developed countries is understudied, there has been even less discussion of this area in emerging economies (e.g., Vietnam). This is indeed troubling, as Vietnam, while still emerging, has a fast-growing economy [51], one of the fastest in Asia, exceeding 7\% annually [52], and one where its citizens enjoy ever increasing standards of living and sizable disposable incomes [53], the result of which contributes to higher consumer spending and WTP, especially in the apparel market [54].

Another point making Vietnam a worthy context representative of emerging economies is that Vietnam has similarly experienced the negative impacts of growing PET-bottle waste $[52,55]$. As such, Vietnam's government and citizens have shown an increased interest in recycling solutions for PET bottles $[56,57]$. Following this, as in developed economies, several solutions have been explored (e.g., using rPET bottles in the production of home furnishings [58], construction materials (concrete) [59], and road asphalt [60]). However, research into consumer PI of rPET bottle-based apparel in this region is underexplored.

Accepting that consumer PI of rPET bottle-based apparel in emerging economies (e.g., Vietnam) remains a neglected area, this study is intended to fill that gap. The purpose 
of this study, therefore, is to explore the market potential (consumer PI) related to rPET bottle-based apparel in the Vietnamese apparel market. To meet this objective, our study looks to the usability of a model posed for use in developed economies, specifically, the applicability (e.g., replicability and generalizability) of using Calvo-Porral and LevyMangin's [29] predictive PI model for developed economies in the context of this study, an emerging economy (i.e., Vietnam). To explore this, our study replicates and thus attempts to extend their model [29] to the Vietnamese context.

Replicability, the intention of this study, as stated by the National Academies of Sciences [61], involves applying the same scientific question with new data collection and similar methods to a new context. This is strongly related to generalizability theory (GT), the extent that the results of a study apply to other contexts or populations that differ from the original one. GT, Strube [62] explains, allows for the precise estimation of reliability, and is a general-purpose approach to investigating broad questions about the consistency or dependability of measurement. Such dependability is especially important when considering PLS models, the type of model replicated in this study [29], as the goal of PLS modeling is to "predict the output value of new cases by applying the model parameters estimated from one data sample to generate predictions for individual cases outside of that sample" ([63], p. 4553).

In addition to the empirical need for replicability, a very practical one is requisite. That is, companies often accept model market predictions without the additional empirical testing needed to establish the applicability of constructs and measures to a second country, a problem all too common in cross-national marketing research and international business studies [64]. This is because, as Durvasula et al. [64] continue, concepts and measures developed in one country are often mistakenly accepted as relevant in other countries without empirically examining their cross-national applicability. This is indeed a concern as applicability basically implies that "the construct is expressed in a similar way in all countries of interest, and therefore has similar levels of reliability and validity" ([64], p. 469).

Accepting the need to test the generalizability of models created for use in developed economies in the context of an emerging one, the research hypotheses for this study were adapted from Calvo-Porral and Levy-Mangin's [29] model for the purpose of replicating and extending their model to test its generalizability to the emerging economy context chosen for this study, Vietnam.

The hypotheses are as follows:

Hypothesis 1 (H1). Quality: The perceived product quality of recycled products has a negative influence on consumers' PI.

Hypothesis 2 (H2). Image: The positive/favorable image of recycled products has a positive influence on consumers' PI.

Hypothesis 3 (H3). Sustainability: The sustainability of recycled products has a positive influence on consumers' PI.

Hypothesis 4 (H4). Safety: The perceived safety of recycled products has a negative influence on consumers' PI.

In accordance with green consumerism, rPET bottle-based apparel is commonly associated with waste reduction, and thus this study is timely in that it fits into Vietnam's current ecological goals of reducing environmental pollution associated with the apparel industry [65]. As such practices also have the potential to produce new markets, rPET bottle-based apparel additionally fits into the Vietnamese government's current economic growth objectives [66]. Our study is also of practical use for the global apparel industry, as companies keen to gain advantage in the Vietnamese market need a better understanding of consumer behavior [23]. That is, in an emerging economy such as Vietnam, the findings of our study can aid apparel manufacturers and marketing specialists in the identification 
of how to better support the future expansion of the market for postconsumer rPET bottlebased garments in the apparel industry.

\section{Methods}

This study tested the applicability of extending a model developed for use in developed economies [29] to an emerging one (i.e., Vietnam), a model which drew on green consumerism factors found to influence PI in developing economies (i.e., quality, image, sustainability, safety). Specifically, Calvo-Porral and Levy-Mangin's [29] PI model was chosen, as this model had previously been utilized to explore consumer PI of recycled plastic-sourced apparel in a developed country (i.e., Spain).

In the interest of replicability, the original model's [29] methods, analyses, and reporting procedures were followed. For instance, a five-point Likert questionnaire was adopted. In line with replicability, identical wording was also used (Table 1), and each latent variable had three indicators. However, to adapt the survey for the intended context, the questionnaire was translated into the consumers' L1 (Vietnamese), checked by native speakers $(\mathrm{N}=2)$, and then piloted with a number of respondents $(\mathrm{N}=30)$ to explore any ambiguities in the translation, after which the questionnaire was sent via SMPs (Facebook, Instagram, Zalo) to networkers across a variety of social groups in order to reduce researcher bias. Networkers who responded were then asked to share the link with other networkers in their circles. Respondents self-administered the questionnaire, as using SMPs for survey distribution and data collection is useful when respondents are difficult to identify or contact [67]. The descriptive measures of means and standard deviations are shown in Table 1.

Table 1. Measurement Scale, Indicators, and Descriptive Measures.

\begin{tabular}{|c|c|c|c|}
\hline Variables & Indicators & Mean & Standard Deviation \\
\hline \multirow{3}{*}{ Perceived Quality } & Qual1: Recycled products have good quality & 3.689 & 0.816 \\
\hline & Qual2: Recycled products give me the quality that I expect & 3.638 & 0.782 \\
\hline & $\begin{array}{l}\text { Qual3: Recycled products have a quality similar to that of products that } \\
\text { are not sustainable }\end{array}$ & 3.298 & 0.939 \\
\hline \multirow{3}{*}{ Product Image } & Img1: I have a positive image of recycled products & 3.442 & 1.219 \\
\hline & $\begin{array}{l}\text { Img2: Consumers of recycled products know how to buy } \\
\text { (buy intelligently) }\end{array}$ & 3.497 & 1.041 \\
\hline & Img3: Recycled products have a positive/favorable image in the market & 3.520 & 1.253 \\
\hline \multirow[t]{2}{*}{ Sustainability } & $\begin{array}{l}\text { Sust1: Recycled products respect the environment/are good for } \\
\text { the environment }\end{array}$ & 4.503 & 0.600 \\
\hline & Sust2: Recycled products offer significant environmental benefits & 4.423 & 0.656 \\
\hline \multirow{3}{*}{ Safety } & Saf1: Recycled products are safe for consumers & 3.803 & 0.876 \\
\hline & Saf2: The production process of recycled products is safe and reliable & 3.567 & 0.863 \\
\hline & Saf3: Recycled products are benign and not harmful & 3.558 & 0.909 \\
\hline \multirow{3}{*}{ Purchase Intention } & Int1: I will buy recycled products in the future & 4.085 & 0.695 \\
\hline & Int2: I am likely to buy recycled products & 4.140 & 0.664 \\
\hline & Int3: I will continue buying recycled products & 3.958 & 0.743 \\
\hline
\end{tabular}

Prior to answering the questions, the research topic was, as with the original model [29], introduced to the participants. The next section collected demographic and economic data. Following this, the participants were asked to rate the variables related to their PI. A total of 495 responses were received, 473 of which provided usable data (i.e., duplicates were removed), a medium-sized sample exceeding the minimum size for partial least square models $[68,69]$. The respondents consisted of 343 females, 117 males, 7 other, and 6 preferred not to disclose gender. Ages included 12-20 (116), 21-30 (290), 31-40 (59), 41-50 (5), 51-60 (3). Education levels included those who had studied junior high school (8), high school (38), university (402), master (24), and PhD studies (1). Those with an urban 
domicile consisted of 411, and 62 cited rural. Monthly income included less than 5,000,0000 (260), 5,000,000 to 15,000,000 (164), 15,000,000 to 25,0000 (28), and over 25,000,000 VND (21).

To analyze the data, in keeping with replicating the procedures used in the original study [29], partial least squares structural equation modeling (PLS-SEM) software was utilized, as PLS-SEM has been found to be an effective method for predicting multiequation econometric models [68,69] (i.e., it enables path analysis, theory exploration, and the ability to model multiple dependent and independent latent variables to make stronger predictions [69]). Specifically, professional version Smart PLS-SEM 3.3 was used for hypothesis testing, assessing the significance at a $95 \%$ confidence interval or more throughout the algorithm and bootstrap statistics.

After the results were obtained and analyzed, they were compared to the original study's [29] findings to determine the applicability (generalizability) of using the original model for emerging economies (e.g., the context of this study, Vietnam).

\section{Results}

To test the original model [29], PLS-SEM path modeling was used to examine the proposed model and to test its hypotheses. In keeping with replicability, our findings are reported and ordered in a similar fashion as the original study [29]. Prior to testing the paths and coefficients, the proposed model, in accordance with PLS protocol, was tested for reliability, validity, and internal consistency. Internal consistency and reliability were examined using Cronbach alpha (CA) and composite reliability (CR), and convergent validity and discriminant validity for all of the constructs were established (Table 2). Examining the results for the constructs, both CR and CA were above 0.70 , which indicated adequate internal consistency [69]. Convergent validity was determined by factor loadings above the 0.70 cut-off, and average variance extracted (AVE) was above 0.50 [70]. However, standardized loadings, as with the original study [29], indicated the requisite removal of one indicator for quality (Qual3) and one for sustainability (SUST3) from the initial measurement scale, as these had lower factor loadings than 0.70 .

Table 2. Factor Loadings and Indicators of Internal Consistency and Reliability.

\begin{tabular}{|c|c|c|c|c|c|}
\hline Construct & Items & Cronbach Alpha & Standardized Loadings & CR & AVE \\
\hline \multirow{2}{*}{ Perceived Quality } & Qual1 & \multirow{2}{*}{0.813} & 0.914 & \multirow{2}{*}{0.914} & \multirow{2}{*}{0.842} \\
\hline & Qual2 & & 0.922 & & \\
\hline \multirow{3}{*}{ Image } & IMG1 & \multirow{3}{*}{0.750} & 0.753 & \multirow{3}{*}{0.854} & \multirow{3}{*}{0.663} \\
\hline & IMG2 & & 0.797 & & \\
\hline & IMG3 & & 0.887 & & \\
\hline \multirow{2}{*}{ Sustainability } & SUST1 & \multirow[b]{2}{*}{0.773} & 0.879 & \multirow[b]{2}{*}{0.897} & \multirow[b]{2}{*}{0.814} \\
\hline & SUST2 & & 0.924 & & \\
\hline \multirow{3}{*}{ Safety } & SAF1 & \multirow{3}{*}{0.860} & 0.870 & \multirow{3}{*}{0.914} & \multirow{3}{*}{0.781} \\
\hline & SAF2 & & 0.885 & & \\
\hline & SAF3 & & 0.895 & & \\
\hline \multirow{3}{*}{ Purchase Intention } & INT1 & \multirow{3}{*}{0.873} & 0.912 & \multirow{3}{*}{0.922} & \multirow{3}{*}{0.797} \\
\hline & INT2 & & 0.848 & & \\
\hline & INT3 & & 0.916 & & \\
\hline
\end{tabular}

As with the original study [29], discriminant validity was established using paired combinations of constructs (Table 3). According to the criteria, the square root of AVE must be higher than the relationships of other variables. In Table 3, every latent variable demonstrates a higher square root than its relationship with other variables. 
Table 3. Discriminant Validity.

\begin{tabular}{cccccc}
\hline & Quality & Image & Sustainability & Safety & Purchase Intention \\
\hline Quality & $\mathbf{0 . 9 1 8}$ & & & & \\
Image & 0.244 & $\mathbf{0 . 8 1 4}$ & & & \\
Sustainability & 0.502 & 0.169 & $\mathbf{0 . 9 0 2}$ & & \\
Safety & 0.576 & 0.205 & 0.419 & $\mathbf{0 . 8 8 4}$ & \\
Purchase Intention & 0.501 & 0.191 & 0.533 & 0.538 & $\mathbf{0 . 8 9 3}$
\end{tabular}

Note: The diagonals are the square root of the latent variables and indicate the highest in any one column or row. Bolds means PLS statistical reporting bolds the top number of each column for discriminant validity.

The structural model was used to analyze the relationship between the latent variables using the coefficient of determination $\left(\mathrm{R}^{2}\right)$ and effect size $\left(\mathrm{F}^{2}\right)$ (Table 4$)$. Variance inflation factors (VIF) were used to evaluate multicollinearity, and all values were found to be below 5 , indicating no multicollinearity exists in the data. Effect size was evaluated using $\mathrm{F}^{2}$ statistics [71], finding that quality has a small impact on PI, and sustainability and safety have significant medium effects, but image has no significant effect.

Table 4. Evaluation of the Structural Model.

\begin{tabular}{ccccc}
\hline & VIF & Confidence & $\mathbf{F}^{\mathbf{2}}$ & $\mathbf{R}^{\mathbf{2}}$ \\
\hline Quality & 1.737 & $0.058-0.250$ & 0.023 & \\
Image & 1.072 & $-0.030-0.107$ & 0.002 & \\
Sustainability & 1.386 & $0.236-0.402$ & 0.128 & \\
Safety & 1.556 & $0.221-0.395$ & 0.105 & 0.420 \\
Purchase Intention & & & &
\end{tabular}

Table 5 shows the path coefficients of the relationship between PI, corresponding t-values, and the level of significance. The findings show support for three of the four proposed hypotheses: H1 Quality, H3 Sustainability, and H4 Safety. H1 proposed that quality has a significant relationship with PI. The results demonstrated a significant positive relationship with PI ( $\beta=0.154, \mathrm{~T}=3.134, p=<0.01)$. H3 suggested that safety provides a significant contribution to PI. The results acknowledge the significant positive role of safety in PI $(\beta=0.308, \mathrm{~T}=6.945, p<0.01)$. H4 stated that sustainability has a significant effect on PI. The results show a significant positive relationship of sustainability for PI ( $\beta=0.321, T=7.585, p<0.01)$. Examining the results, it can be concluded that the higher the consumer perception of sustainability, safety, and quality, the greater the consumer PI. However, $\mathrm{H} 2$ image was not supported, as this relationship failed to reach statistical significance $(\beta=0.036, \mathrm{~T}=1.020, p=0.308)$.

Table 5. Hypothesis Evaluation.

\begin{tabular}{ccccc}
\hline & Path Coefficient & T Value & $p$ Values & Hypothesis Test \\
\hline Quality $\rightarrow$ INT & $0.154^{* *}$ & 3.134 & 0.002 & H1: Supported \\
Image $\rightarrow$ INT & 0.036 & 1.020 & 0.308 & H2: Not Supported \\
Safety $\rightarrow$ INT & $0.308^{* *}$ & 6.945 & 0.000 & H3: Supported \\
Sustainability $\rightarrow$ INT & $0.321^{* *}$ & 7.585 & 0.000 & H4: Supported \\
\hline
\end{tabular}

Note: Ns $=$ not significant, ${ }^{* *}$ significant $(p<0.05), \mathrm{R} 2$ (Intention to purchase) $=0.420$.

Figure 1 shows the results from the structural model. It was found that the model accounts for $42 \%$ of PI. 


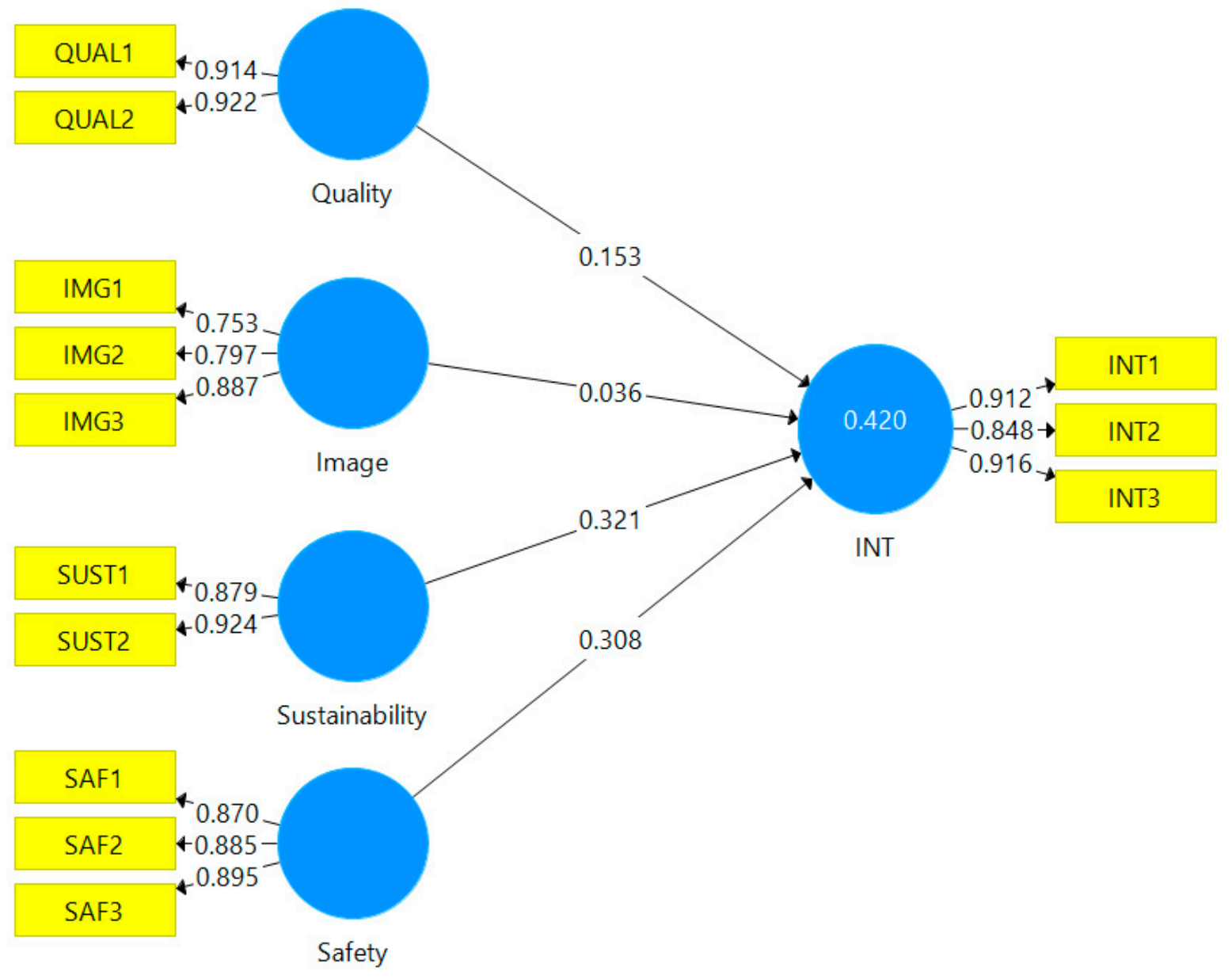

Figure 1. This figure presents the results of the path analysis.

These results may suggest that if consumers have positive perceptions of the quality, sustainability, and safety of apparel made from rPET bottles, concerns for image may not be relevant to consumer PI. These results run counter to the findings of the original model (a model posed for a developed economy [29]) that reported that better product image followed by safety were supported, whereas quality and sustainability were not (Table 6). Therefore, while the structure of the original model is not entirely rejected, it can be concluded that the results of the model may not be entirely generalizable to an emerging economy like Vietnam. Additionally, the results indicated that the present model accounted for $42 \%$ of PI when tested in an emerging economy, whereas the model for developed economies accounted for $69.3 \%$.

Table 6. Comparison of the Results of the Current Study Undertaken in an Emerging Economy (i.e., Vietnam) and a Study Completed in a Developed Economy [29].

\begin{tabular}{lcc}
\hline \multicolumn{1}{c}{ Hypotheses } & $\begin{array}{c}\text { Current Study (Emerging Economy, } \\
\text { i.e., Vietnam) }\end{array}$ & $\begin{array}{c}\text { Previous Study } \\
\text { (Developed Economy) }\end{array}$ \\
\hline H1 Quality & Yes & No \\
H2 Image & No & Yes \\
H3 Sustainability & Yes & No \\
H4 Safety & Yes & Yes \\
\hline
\end{tabular}




\section{Discussion}

This study provides several contributions. First, it supports and advances PI literature with regard to eco-friendly apparel made from rPET bottles in emerging economies (e.g., Vietnam). Literature which found that concern for quality is a driver of PI [33] was supported. Similarly, literature pointing to consumer concern for a sustainable environment, where consumers with higher concerns for the environment are more likely to purchase eco-friendly materials, was supported $[37,38,43]$. Literature regarding product safety was also supported, where consumers demonstrate concerns for product safety due to fears of contagion or lack of knowledge regarding manufacturing processes $[39,48,49]$. However, literature regarding consumer concern for image was not supported [25]. Second, considering the extant literature and the study's results, it is argued that consumer PI in emerging economies may not be entirely congruent with that of developing countries (i.e., as demonstrated by testing the model proposed for developed economies [29]). As such, we posit an extension of the original model's results here for use in emerging economies (e.g., Vietnam). Lastly, considering the findings, this study provides practical guidance for apparel manufacturers and marketing specialists in the identification of how to better support the future expansion of the market for the open innovation-driven technological advance of postconsumer rPET bottle-based apparel in emerging economies (e.g., Vietnam). Following this, the study's findings additionally inform efforts towards Vietnam's current ecological goals of reducing the environmental pollution associated with the apparel industry [64] as well as the Vietnamese government's current economic growth objectives [58,65].

The study also has limitations that need to be addressed. First, the exploration is regionally specific (i.e., one emerging economy, Vietnam), and thus additional studies need to be undertaken both in the larger context of emerging economies as well as in specific regions of Vietnam, as Vietnam is a diverse society with distinct socio-economicdemographic regions. Second, the results indicated that the model accounts for $42 \%$ of PI when tested in an emerging economy, whereas the model posed for a developed economy [29] accounted for $69.3 \%$. These results beg the question regarding what other unexplored variables might account for a larger percentage. Third, several empirical constraints need to be considered. The number of respondents, for example, was medium in number $(\mathrm{N}=473)$, and although PLS is well suited to medium samples [68,69], a larger sample more suited to a country as large and diverse as Vietnam might have been more representative and potentially produced dissimilar results. In line with this, while the socio-demographic makeup of the participants was indicated by the responses rather than any purposeful intent of the sampling procedure, some demographic features were outside Vietnam's census norms. The respondents were, for instance, largely from urban areas, leaving too small a sample to perform an assessment as to whether rural/urban was a mediating factor. Similarly, gender was unequally weighted, with the majority of the respondents being female (73\%). The first factor may be attributable to matters of Internet rural/urban inclusion and disparities [72]. The latter factor may be attributable to women being found to be more concerned with environmental issues [73,74] and therefore more inclined to participate in the questionnaire. However, these factors need to be explored further. It is therefore suggested that these findings be considered preliminary and that future studies take these factors into account. It is also suggested that future studies investigate additional features (e.g., price, WTP) which may contribute to the overall marketing mix of PI toward rPET-based apparel in emerging economies.

Author Contributions: Conceptualization, T.T.A.L.; methodology, J.R.B., T.T.A.L.; software, J.R.B., T.T.A.L.; validation, J.R.B., T.T.A.L.; formal analysis, J.R.B., T.T.A.L.; investigation, J.R.B., T.T.A.L.; resources, J.R.B., T.T.A.L.; draft preparation, J.R.B., T.T.A.L.; writing-review and editing, J.R.B., T.T.A.L.; visualization, J.R.B., T.T.A.L.; supervision, J.R.B., T.T.A.L.; project administration, J.R.B., T.T.A.L. All authors have read and agreed to the published version of the manuscript.

Funding: This research received no external funding.

Data Availability Statement: Data available on request. 
Acknowledgments: T.T.A.L. and J.R.B. gratefully acknowledge the suggestions and ideas of Liang Tsai (Quemoy National University), the statistical analysis contributions of Saqib Sohail, the editing contributions of Stewart Clarke, all those who responded to the survey, and the editors and reviewers of the Journal of Open Innovation: Technology, Market, and Complexity.

Conflicts of Interest: The authors declare no conflict of interest.

\section{References}

1. Chang, Y.; Chen, H.L.; Francis, S. Market applications for recycled postconsumer fibers. Fam. Consum. Sci. Res. J. 1999, 27, 320-340. [CrossRef]

2. Francis, S.K.; Bryant, N.; Butler, S.L.; Chang, Y.; Mumaw, C.; Shim, K.; Swedlund, H.; Wang, H. Clothing Disposition Practices and Attitudes: A Cross-National Exploration; Fashioning Intercultural Perspectives: Lyon, France, July 1997.

3. Rahman, M.T.; Mohajerani, A.; Giustozzi, F. Recycling of waste materials for asphalt concrete and bitumen: A review. Materials 2020, 13, 1495. [CrossRef] [PubMed]

4. $\quad$ Ongpeng, J.M.C.; Barra, J.; Carampatana, K.; Sebastian, C.; Yu, J.J.; Aviso, K.B.; Tan, R.R. Strengthening rectangular columns using recycled PET bottle strips. Eng. Sci. Technol. Int. 2020, 1-9. [CrossRef]

5. Majumdar, A.; Shukla, S.; Singh, A.A.; Arora, S. Circular fashion: Properties of fabrics made from mechanically recycled poly-ethylene terephthalate (PET) bottles. Resour. Conserv. Recycl. 2020, 161, 104915. [CrossRef]

6. Young, C.; Jirousek, C.; Ashdown, S. Undesigned: A study in sustainable design of apparel using postconsumer recycled clothing. Cloth Text. J. 2004, 22, 61-68. [CrossRef]

7. Sung, K. A review on upcycling: Current body of literature, knowledge gaps and a way forward. In Proceedings of the ICECESS 2015: 17th International Conference on Environmental, Cultural, Economic and Social Sustainability, Venice, Italy, 13-14 April 2015.

8. Laville, S.; Taylor, M. A million bottles a minute: World's plastic binge as dangerous as climate change. Guard 2017, 28, 1-6.

9. Nakano, Y. Perceptions towards clothes with recycled content and environmental awareness: The development of end markets. In Ecotextiles; Miraftab, M., Horrocks, A.R., Eds.; Woodhead Publishing: London, UK, 2007; pp. 3-14.

10. Cámara-Creixell, J.; Scheel-Mayenberger, C. PetStar PET bottle-to-bottle recycling system, a zero-waste circular economy business model. In Towards Zero Waste; María-Laura Franco-García, M.L., Carpio-Aguilar, J.C., Bressers, H., Eds.; Springer: Cham, Switzerland, 2019; pp. 191-213.

11. van Emmerik, T.; Schwarz, A. Plastic debris in rivers. WIREs Water 2020, 7, 1-24. [CrossRef]

12. Dunlop, S.W.; Dunlop, B.J.; Brown, M. Plastic pollution in paradise: Daily accumulation rates of marine litter on Cousine Island, Seychelles. Mar. Pollut. Bull. 2020, 151, 110803. [CrossRef]

13. Park, S.H.; Kim, S.H. Poly (ethylene terephthalate) recycling for high value added textiles. Fash. Text. 2014, 1, 1-17. [CrossRef]

14. Payne, A. Open-and closed-loop recycling of textile and apparel products. In Handbook of Life Cycle Assessment (LCA) of Textiles and Clothing; Muthu, S.S., Ed.; Woodhead Publishing: New York, NY, USA, 2015; pp. 103-123.

15. Mukherjee, A. Clothes from plastic bottles! Sci. Rep. 2017, 6, 40-41.

16. Ahmad, A.; Madi, Y.; Abuhashesh, M.M.; Nusairat, N.; Masa'Deh, R. The Knowledge, Attitude, and Practice of the Adoption of Green Fashion Innovation. J. Open Innov. Technol. Mark. Complex. 2020, 6, 107. [CrossRef]

17. Conca, J. Making Climate Change Fashionable-The Garment Industry Takes on Global Warming. 2015. Available online: https: / / www.forbes.com/ (accessed on 15 June 2020).

18. Claudio, L. Waste couture: Environmental impact of the clothing industry. Environ. Health Perspect. 2007, 115, A449-A454. [CrossRef] [PubMed]

19. Niinimäki, K.; Peters, G.; Dahlbo, H.; Perry, P.; Rissanen, T.; Gwilt, A. The environmental price of fast fashion. Rev. Earth Environ. 2020, 1, 189-200. [CrossRef]

20. Russell, S.; Swan, P.; Trebowicz, M.; Ireland, A. Review of wool recycling and reuse. In Natural Fibres: Advances in Science and Technology towards Industrial Application; Fangueiro, R., Rana, S., Eds.; Springer: Cham, Switzerland, 2016; pp. 415-428.

21. Vadicherla, T.; Saravanan, D. Textiles and apparel development using recycled and reclaimed fibers. In Roadmap to Sustainable Textiles and Clothing: Eco-Friendly Raw Materials, Technologies, and Processing Methods; Muthu, S., Ed.; Springer: Singapore, 2014; pp. $139-160$.

22. Bhatt, D.; Silverman, J.; Dickson, M.A. Consumer interest in upcycling techniques and purchasing upcycled clothing as an approach to reducing textile waste. Int. J. Fash. Des. Tech. Educ. 2019, 12, 118-128. [CrossRef]

23. Kanchanapibul, M.; Lacka, E.; Wang, X.; Chan, H.K. An empirical investigation of green purchase behaviour among the young generation. J. Clean Prod. 2014, 66, 528-536. [CrossRef]

24. Zheng, Y.; Chi, T. Factors influencing purchase intention towards environmentally friendly apparel: An empirical study of US consumers. Int. J. Fash. Des. Tech. Educ. 2015, 8, 68-77. [CrossRef]

25. Tsen, C.; Phang, G.; Hasan, H.; Buncha, H. Going green: A study of consumers' willingness to pay for green products in Kota Kinabalu. Int. J. Bus. Soc. 2006, 7, 40-54.

26. Ajzen, I. The theory of planned behavior. Organ. Behav. Hum. Decis. Process. 1991, 50, 179-211. [CrossRef]

27. Fishbein, M.; Ajzen, I. Belief, Attitude, Intention, and Behavior: An Introduction to Theory and Research; Addison-Wesley: Reading, MA, USA, 1975. 
28. Sarabia-Andreu, F.; Sarabia-Sánchez, F.J.; Moreno-Albaladejo, P. A New attitudinal integral-model to explain green purchase intention. Sustainability 2019, 11, 6290. [CrossRef]

29. Calvo-Porral, C.; Lévy-Mangin, J.P. The circular economy business model: Examining consumers' acceptance of recycled goods. Adm. Sci. 2020, 10, 28. [CrossRef]

30. Hahladakis, J.N.; Lacovidou, E.; Gerassimidou, S. Plastic waste in a circular economy. In Plastic Waste and Recycling; Letcher, M.T., Ed.; Academic Press: London, UK, 2020; pp. 481-512.

31. Singhal, D.; Tripathy, S.; Jena, S.K. Remanufacturing for the circular economy: Study and evaluation of critical factors. Resour. Conserv. Recycl. 2020, 156, 104681. [CrossRef]

32. Gallaud, D.; Laperche, B. Circular Economy, Industrial Ecology and Short Supply Chain; Wiley Blackwell: Hoboken, NJ, USA, 2016.

33. Meyer, A. What's in it for the customers? Successfully marketing green clothes. Bus. Strategy Environ. 2001, 10, 317-330. [CrossRef]

34. Chi, T. Consumer perceived value of environmentally friendly apparel: An empirical study of Chinese consumers. J. Text. Inst. 2015, 106, 1038-1050. [CrossRef]

35. Chang, C. Feeling ambivalent about going green. J. Advert. 2011, 40, 19-32. [CrossRef]

36. Kumagai, K. Sustainable plastic clothing and brand luxury: A discussion of contradictory consumer behaviour. Asia Pac. J. Mark. Logist. 2020. [CrossRef]

37. Thongpila, K. Fabricated Future: Applying the Theory of Planned Behavior to Influence Purchaseintention of Green Fashion Made from Recycled Plastic in Thailand. Master's Thesis, Faculty of Textiles, Engineering and Business, University of Borås, Borås, Sweden, 2019.

38. Park, H.J.; Lin, L.M. Exploring attitude-Behavior gap in sustainable consumption: Comparison of recycled and upcycled fashion products. J. Bus. Res. 2018, 117, 623-638. [CrossRef]

39. Vehmas, K.; Raudaskoski, A.; Heikkilä, P.; Harlin, A.; Mensonen, A. Consumer attitudes and communication in circular fashion. J. Fash. Mark. Manag. 2018, 22, 286-300. [CrossRef]

40. Sung, K.; Cooper, T.; Kettley, S. Factors influencing upcycling for UK makers. Sustainability 2019, 11, 870. [CrossRef]

41. Roberts, J.A. Green consumers in the 1990s: Profile and implications for advertising. J. Bus. Res. 1996, 36, 217-231. [CrossRef]

42. Yu, S.; Lee, J. The effects of consumers' perceived values on intention to purchase upcycled products. Sustainability 2019, 11, 1034. [CrossRef]

43. Yoh, E. Effect of moral identity on attitude toward and purchase intention of upcycled fashion products-Comparison of purchasers and non-purchasers. Res. J. Costume Cult. 2018, 26, 409-426.

44. Bickart, B.A.; Ruth, J.A. Green eco-seals and advertising persuasion. J. Advert. 2012, 41, 51-67. [CrossRef]

45. Koenig-Lewis, N.; Palmer, A.; Dermody, J.; Urbye, A. Consumers' evaluations of ecological packaging-Rational and emotional approaches. J. Environ. Psychol. 2014, 37, 94-105. [CrossRef]

46. Matthes, J.; Wonneberger, A. The skeptical green consumer revisited: Testing the relationship between green consumerism and skepticism toward advertising. J. Advert. 2014, 43, 115-127. [CrossRef]

47. Magnier, L.; Mugge, R.; Schoormans, J. Turning ocean garbage into products—Consumers' evaluations of products made of recycled ocean plastic. J. Clean. Prod. 2019, 215, 84-98. [CrossRef]

48. Meng, M.D.; Leary, R.B. It might be ethical, but I won't buy it: Perceived contamination of, and disgust towards, clothing made from recycled plastic bottles. Psychol. Mark. 2019, 1-15. [CrossRef]

49. Girão, T. Sustainable Swimwear in Portugal: Perceptions and Purchase Intentions. Ph.D. Thesis, Universidade Católica Portuguesa, Lisboa, Portugal, 2020.

50. Hazen, B.T.; Mollenkopf, D.; Wang, Y. Remanufacturing for the circular economy: An examination of consumer switching behavior. Bus. Strategy Environ. 2017, 26, 451-464. [CrossRef]

51. Hai, H.T.; Quang, N.D.; Thang, N.T.; Nam, N.H. Circular economy in Vietnam. In Circular Economy: Global Perspective; Gosh, S.K., Ed.; Springer: Singapore, 2020; pp. 423-452.

52. Kawai, K.; Nguyen, T.K.T.; Matsui, S. Physical compositions of municipal solid waste and recyclable waste discharged from households in Hanoi, Vietnam. In Annual Report of FY 2006, The Core University Program between Japan Society for the Promotion of Science (JSPS) and Vietnamese Academy of Science and Technology (VAST); OUKA: Osaka, Japan, 2007; pp. 373-380.

53. Thanh, N.P.; Matsui, Y.; Fujiwara, T. An assessment on household attitudes and behavior towards household solid waste discard and recycling in the Mekong Delta Region-Southern Vietnam. Environ. Eng. Manag. J. 2012, 11, 1445-1454. [CrossRef]

54. Van Huy, L.; Chi, M.T.T.; Lobo, A.; Nguyen, N.; Long, P.H. Effective segmentation of organic food consumers in Vietnam using food-related lifestyles. Sustainability 2019, 11, 1237. [CrossRef]

55. Lee, J.; Nguyen, M.J. Product attributes and preference for foreign brands among Vietnamese consumers. J. Retail. Consum. Serv. 2017, 35, 76-83. [CrossRef]

56. Akenji, L.; Bengtsson, M.; Hotta, Y.; Kato, M.; Hengesbaugh, M. Policy responses to plastic pollution in Asia: A summary of a regional gap analysis. In Plastic Waste and Recycling; Letcher, M.T., Ed.; Academic Press: London, UK, 2020; pp. 531-567.

57. Yokoo, H.F.; Kawai, K.; Higuchi, Y. Informal recycling and social preferences: Evidence from household survey data in Vietnam. Resour. Energy Econ. 2018, 54, 109-124. [CrossRef]

58. Czuba, M. Upcycling as a manifestation of consumer and business behavior that expresses sustainable consumption and determines the functioning of the communal services sector. Prob. Ekor. 2018, 13, 159-163. 
59. Frigione, M. Recycling of PET bottles as fine aggregate in concrete. Waste Manag. 2010, 30, 1101-1106. [CrossRef] [PubMed]

60. Tuan, N.M. Effect of Polyethylene Terephthalate (PET) from plastic waste on strength of hot mix asphalt concrete in southern Vietnam. In Proceedings of the 11th Annual Joint Workshop on Composities, Ho Chi Minh, Vietnam, 9-11 February 2017.

61. National Academies of Sciences, Engineering, \& Medicine. Reproducibility and Replicability in Science; National Academies Press: Washington, DC, USA, 2019.

62. Strube, M.J. Reliability and generalizability theory. In Reading and Understanding MORE Multivariate Statistics; Grimm, L.G., Yarnold, P.R., Eds.; American Psychological Association: Washington, DC, USA, 2000; pp. 23-66.

63. Shmueli, G.; Ray, S.; Estrada, J.M.V.; Chatla, S.B. The elephant in the room: Predictive performance of PLS models. J. Bus. Res. 2016, 69, 4552-4564. [CrossRef]

64. Durvasula, S.; Netemeyer, R.G.; Andrews, J.C.; Lysonski, S. Examining the cross-national applicability of multi-item, multidimensional measures using generalizability theory. J. Int. Bus. Stud. 2006, 37, 469-483. [CrossRef]

65. Nayak, R.; Akbari, M.; Far, S.M. Recent sustainable trends in Vietnam's fashion supply chain. J. Clean. Prod. 2019, 225, 291-303. [CrossRef]

66. Jaax, A. Private sector development and provincial patterns of poverty: Evidence from Vietnam. World Dev. 2020, 127, 104747. [CrossRef]

67. Cooper, D.R.; Schindler, P. Business Research Methods, 12th ed.; McGraw-Hill Education: New York, NY, USA, 2013.

68. Wong, K.K. Mastering Partial Least Squares Structural Equation Modeling (PLS-Sem) with SmartPLS in 38 Hours; iUniverse: Bloomington, Indiana, 2019.

69. Hair, J.F.; Risher, J.J.; Sarstedt, M.; Ringle, C.M. When to use and how to report the results of PLS-SEM. Eur. Bus. Rev. 2019, 31, 2-24. [CrossRef]

70. Fornell, C.; Larcke, D.F. Evaluating structural equation models with unobservable variables and measurement error. J. Mark. Res. 1981, 18, 39-50. [CrossRef]

71. Cohen, J. Statistical Power Analysis for the Behavioral Sciences; Erlbaum: Hillsdale, NJ, USA, 1988.

72. Thai, D.M.; Falch, M. Universal service in Vietnam: An institutional approach. Telecommun. Policy 2018, 42, 323-332. [CrossRef]

73. Xiao, C.; McCright, A.M. Gender differences in environmental concern: Revisiting the institutional trust hypothesis in the USA. Environ. Behav. 2015, 47, 17-37. [CrossRef]

74. Dhir, A.; Sadiq, M.; Talwar, S.; Sakashita, M.; Kaur, P. Why do retail consumers buy green apparel? A knowledge-attitudebehaviour-context perspective. J. Retail. Consum. Serv. 2020. Available online: https://www.sciencedirect.com/science/article/ pii/S0969698920314065 (accessed on 30 December 2020). [CrossRef] 